\title{
EDUCAÇÃO DISCIPLINAR OU LIBERTADORA? UMA REFLEXÃO A PARTIR DAS PERSPECTIVAS FREIRIANA E FOUCAULTIANA
}

\author{
Marcelo Bezerra de Morais ${ }^{1}$ \\ Themis Barros de Menezes ${ }^{2}$
}

\begin{abstract}
RESUMO
Partindo da seguinte indagação: Qual a educação que almejamos para nossas instituições escolares e, consequentemente, para a formação dos sujeitos? Temos, com este artigo, o objetivo de refletir teoricamente sobre o papel da educação escolar, buscando compreender se almejamos uma educação disciplinar ou libertadora, partindo de algumas compreensões conceituais presentes na obra de Michel Foucault e Paulo Freire. O primeiro nos alerta à importância de pensar as práticas de vigilância na escola e a formação disciplinar dos sujeitos, o segundo orienta que a escola não é neutra e que há a necessidade de educar para a liberdade. Embora pareça utópica pensar nesta educação, apontamos a imperiosa urgência de trabalharmos de modo a compreender cada vez mais os sujeitos e suas necessidades no processo educacional, inquirindo-nos sobre as práticas estabelecidas, as verdades sociais, os conceitos cristalizados, os interesses do mercado e as práticas veladas de opressão.
\end{abstract}

Palavras-chave: Educação crítica; Opressão; Corpos dóceis; Sujeito; Formação humana.

\section{DISCIPLINARY OR LIBERATING EDUCATION? A REFLECTION FROM THEFREIRIAN AND FOUCAULTIAN PERSPECTIVES}

We start from the question: What kind of education do we aim to our school institutions and, consequently, to the subjects formation? With this article, we aim to reflect theoretically on the role of school education, seeking for understand whether we aim to a disciplinary or liberating education, starting from some conceptual understandingspresent in the work of Michel Foucault and Paulo Freire. The first author allows thinkingabout surveillance practices at school and subjects' disciplinary training; the second warns us about the school is not neutral and there is a need to educate for freedom. Although it seems utopian to think about this education, we point out the urgency to work in order to understand more and more the subjects and their needs in the educational process, inquiring about

\footnotetext{
1 Docente do Programa de Pós-Graduação em Ensino (UERN/UFERSA/IFRN) e da Faculdade de Educação da Universidade do Estado do Rio Grande do Norte. Doutor em Educação Matemática (Unesp/ Campus Rio Claro). Membro do Grupo História Oral e Educação Matemática (Ghoem). E-mail:morais.mbm@gmail.com.

2 Graduada em Pedagogia pela Faculdade de Educação da Universidade do Estado do Rio Grande do Norte. E-mail: themis_menezes@hotmail.com.
}

Rev. Omni. Sapi., Mossoró, v.1, n.1, p. 37-51, ago./nov. 2021. DOI: $10.29327 / 240437.1 .1-3$

(c) (i) Esta obra está licenciada com uma Licença 
established practices, social truths, crystallized concepts, market interests and veiled practices of oppression.

Keyword: Critical education; Oppression; Docile bodies; Subject; Human formation.

\section{INTRODUÇÃO}

- E... professora... - Felipe continuou - quem é que diz quais são as coisas que devo aprender? Quem foi que colocou em fila as coisas que devo aprender?

- Quem põe os conhecimentos em fila são pessoas muito inteligentes, do governo.

- E como é que eles sabem o que quero aprender, se não me conhecem e moram longe de mim?

- A escola não é para você aprender aquilo que quer - disse a professora. - A escola é para você aprender aquilo que deve aprender. O que você deve aprender é aquilo que disseram os homens inteligentes do governo. Tudo na ordem certa. Uma coisa de cada vez. Todas as crianças ao mesmo tempo. Na mesma velocidade... (ALVES, 2010, p. 30).

Educação, ensino, aprendizagem, professor, aluno, saberes... todos esses elementos, e outros mais, estão presentes, de algum modo, na escola. Se pesquisarmos no dicionário formal da língua portuguesa, encontraremos para esta palavra, dentre outros, significados como: "1. Instituição pública ou privada que tem por finalidade ministrar ensino coletivo [...]; 3. Prédio onde funciona essa instituição; 4. Sistema, doutrina ou tendência de pensamento de indivíduo ou de grupo de indivíduos que se destacou em algum ramo do conhecimento"3. Mas, e para os alunos, sujeitos envolvidos com essa instituição, que a vivenciam cotidianamente, qual o significado dela e dos saberes nela trabalhados para as suas vidas? ${ }^{4}$ (Figuras 1,23 ).

Figura 1 - Resposta de um aluno do $5^{\underline{a}}$ ano, de uma escola pública de Mossoró, à solicitação de representar o que a escola significa para ele. Na justifica ao desenho eleescreve: "Significa estudar, não teimar, não teimar, não bagunçar, obedecer ao profe[sic] e tem que estudar pra ser algo na vida"

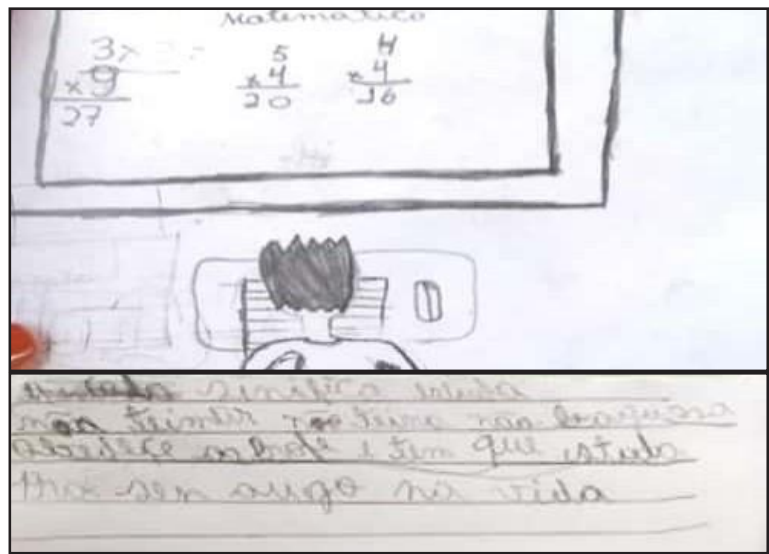

Fonte: Imagens cedidas por Débora Dantas Silva, (2018).

\footnotetext{
${ }^{3}$ Significados encontrados no Dicionário Brasileiro de Língua Portuguesa Michaelis, disponível online em: https://michaelis.uol.com.br/busca? $r=0 \& f=0 \& t=0 \&$ palavra=escola. Consulta realizada em: 01/12/2020. ${ }^{4}$ Apesar da não usualidade na mobilização de imagens dessa forma em introduções de textos acadêmicos, optamos por lançar mão deste recurso por entendermos que elas potencializam as problematizações que aqui desejamos promover e pôr em debate.
} 
Figura 2 - Produções de duas alunas do curso de Pedagogia da Universidade do Estadodo Rio Grande do Norte, em 2018 e 2020, da esquerda para a direita, quando solicitadoque representassem como seria a matemática se esta assumisse uma forma.
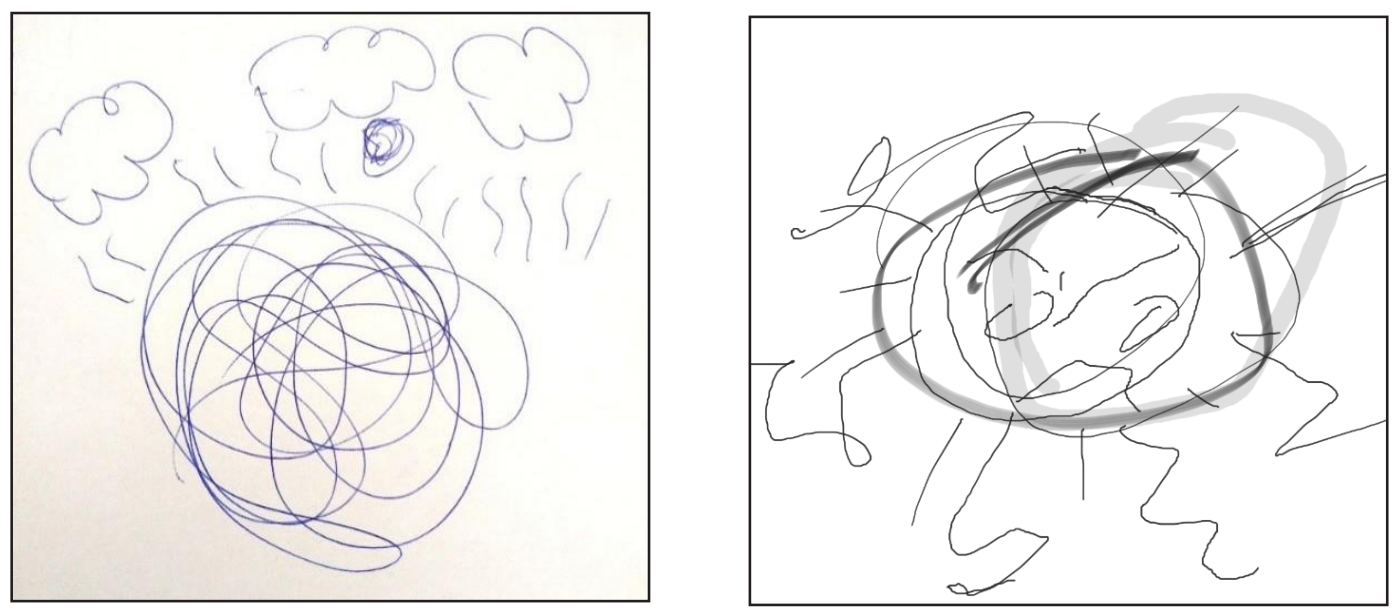

Fonte: Imagens cedidas por Débora Dantas Silva, (2018).

Figura 3 - Excerto de uma produção de uma aluna do curso de Direito da Universidadedo Estado do Rio Grande do Norte, em 2017, quando solicitado no componente de Didática que produzisse uma autobiografia sobre seu processo de escolarização.

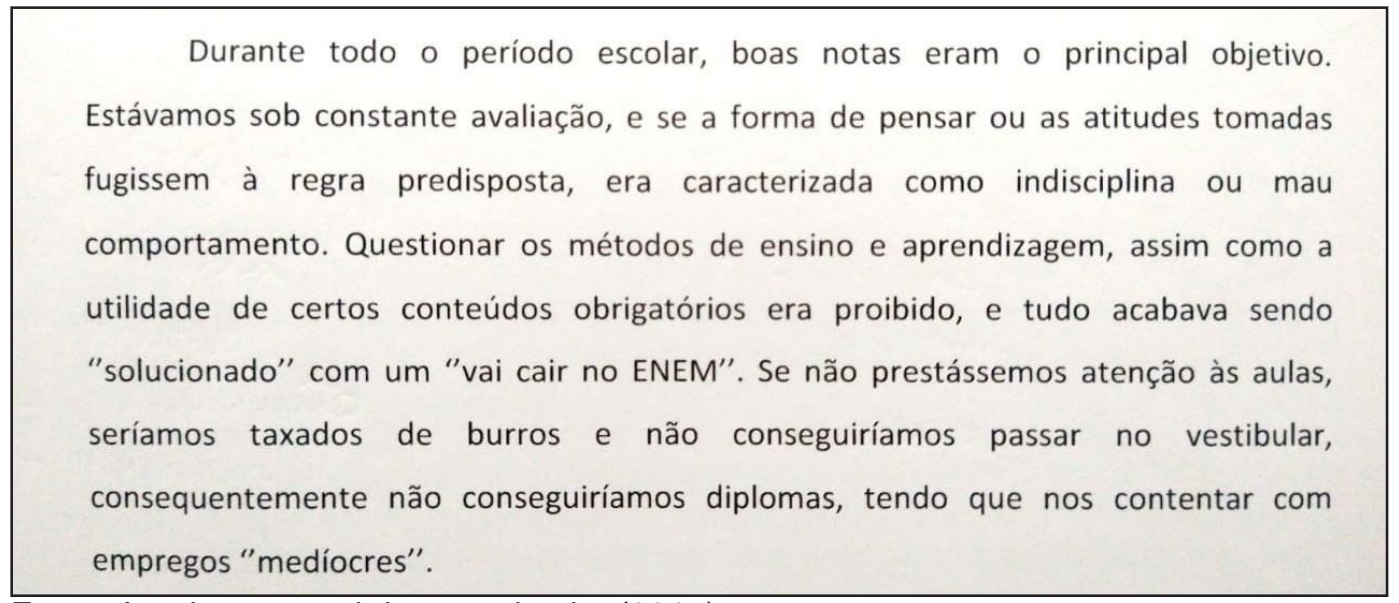

Fonte: Arquivo pessoal do pesquisador (2017).

Esses registros recentes, de diferentes sujeitos, em diferentes espaços formativos e com diferentes histórias de vidas, são sintomáticos e significativos para revelar que aquilo que Rubem Alves (2010) provocou e denunciou em "Pinóquio às avessas", aqui brevemente representado no epílogo, ainda é algo presente nas instituições escolares: uma educação voltada à formação de mentes reprodutoras, pouco pensantes, não criativas, não curiosas, não autônomas, não, não, não...

Mas, este deve ser o papel da escola e da educação formal? Qual a educação que almejamos para nossas instituições e, consequentemente, para a formação dos sujeitos? Com este artigo, intentamos refletir teoricamente sobre o papel da educação escolar, buscando compreender se desejamos uma educação disciplinar ou libertadora, partindo de compreensões conceituais elaboradas por Michel Foucault (1926-1984) e 
Paulo Freire (1921-1997).

Foucault dedicou seus estudos e pesquisas buscando compreender diversos setores e campos da vida social e humana, desde a questão genealógica até questões ligadas às subjetividades de cada ser, daí a sexualidade ser tão mencionada em suas obras. Mesmo tratando essas questões em textos ou trabalhos na área social, para Foucault o sujeito era o produto dos discursos que permeavam um determinado regime histórico, vivendo em constantes relações de poder, sobre as quais também exerce, ou não, o seu poder.

Já Freire dedicou seus estudos a refletir sobre os processos educativos e compreendia que todos são condicionados pelas estruturas econômicas, mas não totalmente determinados. Assim, para ele, a história é possibilidade, rejeitando a inexorabilidade do amanhã e, por isso, lutar se torna muito mais do que um ato político, é uma categoria existencial e histórica. Em sua teoria, a economia, a tecnologia e a ciência exercem um "poder" na vida do ser humano, implicando muitas vezes na renúncia da capacidade de pensar, de comparar, de escolher, de decidir, de projetar, de sonhar, sendo a política uma forma natural dos seres estarem no mundo e com o mundo. Assim, defendia a necessidade de conscientizar os sujeitos sobre sua presença no mundo e a possibilidade de mudá-lo.

Foucault (2010a; 2010b; 1988), em seus trabalhos "Microfísica do poder", "Vigiare Punir: nascimento da prisão" e "História da Sexualidade I: a vontade de saber" nos mostra o quão é importante pensar as práticas de vigilância na escola e a formação disciplinar dos sujeitos. Já Freire (1980; 2005; 1996; 2000), em obras como "Educação como prática da Liberdade", "Pedagogia do Oprimido", "Pedagogia da autonomia: saberes necessários à prática educativa" e "Pedagogia da indignação: cartas pedagógicas" e outros escritos, orienta que a escola não é neutra e que há a necessidade de educarpara a liberdade. São compreensões como essas que buscaremos pôr em diálogo, possibilitando, quiçá, novas compreensões e olhares sobre os processos educativos e ainda as potencializações dos sujeitos, dos saberes e das instituições.

\section{ELEMENTOS PARA PENSAR A EDUCAÇÃO APARTIR DA TEORIA FOUCAULTIANA}

Não restam dúvidas sobre a contribuição que Foucault deu para pensar a educação, oferecendo instrumentos de análise no âmbito histórico, sociológico e filosófico, possibilitando contemplar temas como genealogias dos alunos, estudantes, professores e conselheiros/orientadores; as construções sociais das crianças, da adolescência e da juventude; a escola como forma institucional mutante, o surgimento das disciplinas escolares e de sua relação com os regimes de disciplina e punição; estudos sobre conceitos educacionais que cresceram com o humanismo europeu, em especial nas formações do lluminismo e especificamente kantianas - homem, liberdade, autonomia, punição, governo e autoridade (FERREIRA, 2000; PETERS; BESLEY, 2008).

Verificando em todos os casos, o arquivo foucaultiano revela uma abordagem para questionar conceitos e práticas que pareciam imutáveis e inadequados à uma análise, que pareciam, em outras palavras, institucionalizados, ossificados e destinados à repetição interminável na compreensão e nas interpretações acadêmicas dos grandes estudiosos. Após a contribuição de Foucault, é preciso atentar e revisitar para questões relacionadas ao poder, conhecimento, subjetividade e liberdade na educação.

Buscando refletir sobre o poder a partir da obra foucaultiana (FOUCAULT, 1988; 2010a; 2010b), percebe-se que o autor segue seu caminho intentando explicitar as maneiras pelas quais os seres humanos se formam ou são constituídos como sujeitos, 
onde o processo de poder se manifestaria como aspecto integral da produção de discursos direcionados à verdade. Em especial, o centro de todo processo seriam os seres humanos. Ao se trabalhar o modo pelo qual os homens transformam a si mesmos em suas ações, Foucault (1988) elege a sexualidade como estudo acentuado na tentativa de maiores esclarecimentos sobre o ser humano e seu próprio domínio.

Nesta perspectiva, o poder apresenta inúmeras faces, envolvendo distintos lugares de âmbito social, implicando em não apresentar um aspecto específico e, sim, fazendo surgir vários modos de expressão e compreensão sobre ele, entre essas, a noção de que exercer o poder pode ser aspecto relevante e positivo e também que ele foi criador de práticas e instituições, sendo tudo isso produto do próprio sujeito e das suas relações sociais.

Vale ressaltar que o poder, na vida do ser humano, é exercido de modos diferentes por cada pessoa, o que dependerá diretamente do contexto no qual está inserido. Dependendo de sua intensidade, o poder faz revelar como cada um se manifesta em seu lugar de atuação, até que ponto pode atuar e quais as dimensões em que ele tem seu grau de intensidade. Para o pensador, quando o ser humano exerce seu poder deixa explicitar, muitas vezes, o que estava em seu interior, deixando-se manifestar de forma oportuna para desenvolver os planos antes contidos somente em seu íntimo. Na concepção de Foucault, o poder se apresenta como característica da organização do espaço e do tempo e, nas suas diversas formas de se expressar. Uma das faces desse exercício do poder é aquela que o autor denomina de poder disciplinar, que tem o objetivo de "adestrar" as "multidões confusas e inúteis de corpos", instituindo indivíduos obedientes (FOUCAULT, 2010b, p. 164), e no qual a vigilância pode aparecer como principal instrumento de controle.

Instituições como escola, hospitais, prisões, quarteis e conventos surgem como âmbitos onde a vigilância, o controle e a disciplina atuam sobre os corpos do homem, intervinda em seu comportamento de um modo geral. Essas instituições precisam de observações e dados para chegarem a um diagnóstico preciso dos sujeitos que estão sob suas tutelas. Assim, um diagnóstico prévio é fundamental no processo, sendo esse obtido por técnicas como testes, entrevistas, interrogatórios, consultas e observações, demonstrando uma dominação por meio das tecnologias, quando utilizadas. Todas essas práticas são vivenciadas não apenas para que se adquiram respostas a respeito da identidade pessoal de cada indivíduo, mas para que se delineie uma alteração em seu comportamento pessoal e/ou coletivo (FOUCAULT, 2010b).

Nesse sentido, disciplinar é exercer um tipo de poder, é transformar os sujeitos em objetos e, consequentemente, instrumentos desse exercício.

A disciplina não pode se identificar com uma instituição nem com um aparelho; ela é um tipo de poder, uma modalidade para exercê-lo, que comporta todo um conjunto de instrumentos, de técnicas, de procedimentos, de níveis de aplicação, de alvos; ela é uma 'física' ou uma 'anatomia' do poder, uma tecnologia (FOUCAULT, 1988, p. 34).

A disciplina cabe em todo contexto como um instrumento fundamental que permite a todos os profissionais, principalmente na área da educação, o controle de corpos e a formatação de comportamentos, pois se caracteriza como parte do conjunto de técnicas para se exercer o poder a partir do que cada indivíduo necessita dessa política, caminhando de forma positiva e produtiva para que, consequentemente, a sociedade seja beneficiada, pois a disciplina, em todo e qualquer âmbito da sociedade, se manifesta para que o ser humano possa dar continuidade a sua trajetória de vivência social com seus pares e de modo controlado por alguns.

No espaço escolar, a composição minuciosamente calculada das forças se 
utiliza de um amplo conjunto de técnicas, que vai desde o sinal que marca, dentre outras coisas, o início e o fim das atividades - horário - à distribuição dos alunos de acordo com certas "identificações": classe dos alunos mais "fortes", classe daqueles que apresentam dificuldade na aprendizagem, classe dos "repetentes", etc. Foucault (2010b, p. 38) acrescenta:

\begin{abstract}
A escola torna-se um aparelho de aprender onde cada aluno, cada nível e cada momento, se estão combinados como deve ser, são permanentemente utilizados no processo geral de ensino. (...) O treinamento de escolares deve ser feito da mesma maneira; poucas palavras, nenhuma explicação, no máximo um silêncio total que só seria interrompido por sinais-sinos, palmas, gestos, simples olhar do mestre, ou ainda aquele pequeno aparelho de madeira que os Irmãos das Escolas Cristãs usavam; era chamado por excelência o "sinal" e devia significar em sua brevidade maquinal ao mesmo tempo a técnica do comando e a moral da obediência. (...) O aluno deverá aprender código dos sinais e atender automaticamente a cada um deles.
\end{abstract}

Para Foucault, o sucesso do poder disciplinar, está em três instrumentos simples: "o olhar hierárquico, a sanção normalizadora e sua combinação num procedimento que the é específico, o exame" (FOUCAULT, 2010b, p. 164). O olhar hierárquico com suas posturas e objetivos, a sanção normalizadora como forma de conscientizar e obviamente "educar", e o exame, que requer por parte do educando um melhor conhecimento no que se refere aos estudados, são instrumentos ainda muito presentes nas instituições escolares e são mobilizados como ferramentas importantes para que cada aluno tenha ciência do que ele aprende e o patamar que foi alcançado.

É por meio dessa disciplina que são docilizados os corpos. "É dócil um corpo que pode ser submetido, que pode ser utilizado, que pode ser transformado e aperfeiçoado. [...] em qualquer sociedade, o corpo está preso no interior de poderes muito apertados, que lhe impõem limitações, proibições ou obrigações" (FOUCAULT, 2010b, p. 118). Docilizar o ser humano em seu corpo refere-se a um processo que visa necessidades futuras, processo que o corpo do sujeito passa previamente para estar apto ao trabalho. Dito de outro modo, o ser humano necessita de um processo prévio de assujeitamento, no qual será docilizado antes de ser submetido a atuar em campos mais complexos, como em seus trabalhos/funções, de modo a ser mais produtivo. São mudanças que devem ocorrer constantemente em uma política de conhecimento do próprio corpo.

Esse conhecimento, bem como o estudo do corpo e da sexualidade do homem, vem sendo ampliado desde a Grécia antiga. Durante muitas décadas o homem se omitiu de expor seu corpo como forma de uma expressão corporal. À medida que a humanidade quebra diversos tabus, o que antes parecia proibido, vai possibilitando outras interpretações do próprio ser humano, explicitando que através do seu próprio corpo muitos questionamentos podem ser revelados (FOUCAULT, 1988).

Historicamente, estas compreensões revelam a necessidade de conhecer primeiramente o homem e seu próprio corpo, bem como as relações que estabelece com o exercício do poder, e, consequentemente, a sociedade com seus ajustes e necessidades, para que se possa facilmente inserir na sociedade homens docilizados de forma satisfatória, sem muitas imposições, exercendo sua jornada de maneira produtiva e de modo coletivo. A mulher entra em todo esse contexto como a figura de procriação e do trato com os afazeres das crianças, cuidando e orientando com o básico dos ensinamentos (FOUCAULT, 1988).

As instituições escolares, em particular as tradicionalistas, como os internatos, com todas as suas burocracias, apresentam características de docilização ainda mais fortemente, como se o ser humano dócil pudesse, por isso, adquirir conhecimento com mais facilidade. É forte nessas posturas o poder está centrado nas mãos do professor, 
que é visto como detentor do poder e do saber com exclusividade, muito alusivo ao capitalismo, conforme a sociedade em que vivemos.

(Re)pensar a educação e as práticas de ensino a partir dessa perspectiva do poder, da disciplina e docilização de corpos de Foucault é imprescindível para que se possa buscar a formação de sujeitos cada vez mais autônomos, críticos e livres. Neste ponto, Freire tem muitas contribuições à educação, algumas das quais serão também mobilizadas nesse trabalho.

\section{ALGUMAS NOÇÕES DO LEGADO DE PAULO FREIRE À EDUCAÇÃO}

As pessoas que optam por atuar como profissionais no âmbito educacional devem ter um cuidado muito rigoroso, um compromisso com o seu trabalho no processo de formação dos sujeitos, possibilitando que se tornem adultos capazes de exercer sua cidadania em uma sociedade que se apresenta tão cheia de diferenças e desafios. Nesse sentido, devemos lembrar o que nos ensina Freire (1996), quando fala que ensinar exige comprometimento. É importante lembrar, também, que o autor fala da necessidade da amorosidade do educador "Como prática estritamente humana, jamais pude entender a educação como uma experiência fria, sem alma, em que os sentimentos e as emoções, os desejos, os sonhos devessem ser reprimidos por uma espécie de ditadura racionalista" (FREIRE, 1996, p. 164).

Norteados pelas ideias de Freire (1980; 1996; 2005), entendemos que o ser humano não pode ser visto simplesmente como algo que requer cuidados para seu corpo, pois é essencial que sua totalidade seja trabalhada, como gosto, preferência e tudo que possa ser inserido em sua vivência como positivo. Além disso, os seus saberes precisam ser respeitados e considerados pelo educador. Assim, é preciso questionar acerca do que está sendo feito para que a criança sinta prazer em estudar, ficar em sala de aula em busca de uma nova aprendizagem e, acima de tudo, tornar-se ciente de que todo trabalho que o educador realiza está sendo oferecido de forma satisfatória para o educando.

A liberdade é um aspecto que deve se fazer presente entre o educador e o educando e é visto como ferramenta fundamental, pois possibilitará experiências que serão utilizadas em toda trajetória de vida por ambas as partes. Vale ressaltar, contudo, que a perspectiva de liberdade que Freire (2005) defende não é aquela na qual a liberdade é simplesmente dada ou conquistada por um único sujeito, e, sim, que é uma construção coletiva, a qual se produz em comunhão, o que requer de cada sujeito que ele "seja ativo e responsável, não um escravo nem uma peça bem-alimentada da máquina. Não basta que os homens não sejam escravos; se as condições sociais fomentam a existência de autômatos, o resultado não é o amor à vida, mas o amor à morte." (FREIRE, 2005, p.76), por isso a necessidade de construir individual e socialmente práticas para a liberdade.

Esse é um processo e, como tal, ocorre com o tempo e necessita de engajamento dos diferentes sujeitos no processo. Não se pode esperar sujeitos prontos porque todos os homens estão constantemente se formando, sendo necessário e imprescindível que todo educador esteja preparado para desenvolver suas atividades com toda serenidade possível, ciente dessa realidade. (FREIRE, 1996).

$\mathrm{O}$ ato de ensinar jamais pode ser visto como uma transmissão de conteúdos ou informações por parte do educador, mas como algo que ultrapassa essa compreensão. A prática educativa é um chamado a novos conhecimentos, a novas aprendizagens e, acima de tudo, a novas buscas e descobertas. Cabe ao educador preparar o espaço, disponibilizar materiais e planejar situações de modo a oferecer aos educandos oportunidades de criar e participar dos processos de aprendizagem, de modo a proporcionar e contribuir para que o sujeito desenvolva seus aspectos cognitivo, social, 
físico e motor.

No ato de educar e com vistas a essa formação para a liberdade, é imprescindível que se valorize a leitura que o aluno traz do seu cotidiano. Sobre isso, Freire (1996, p. 27) afirma que "respeitar a leitura de mundo do educando significa torná-la como ponto de partida para a compreensão do papel da curiosidade, de modo geral, e da humana, de modo especial, como um dos impulsos fundantes da produção do conhecimento", assim, é preciso partir dessas leituras de mundo para que a produção de conhecimento seja impulsionada.

O pensamento de Freire nos permite compreender que a produção do conhecimento que é trabalhada na escola deve partir das experiências dos educandos fazendo uma relação entre sua vida e a sala de aula, contribuindo para novas descobertas e aprendizagens. A escola tem um papel fundamental na relação que o aluno estabelece com a leitura, no sentido de formar leitores que reconheçam a importância dessa habilidade como ferramenta essencial não só para a escola ou academia, mas também na formação cidadã (FREIRE, 1989; 1980; 2002).

Revendo a importância da educação, como sendo uma prática social, o pensador aponta que 0 ato de educar não pode restringir-se a ser puramente livresco, teórico, descompromissado com a realidade local dos sujeitos educandos e com o mundo em que vivemos. Por isso, a cara noção, para Freire, de que educar é também um ato político e, portanto, é necessário retomar esse sentido da educação. De acordo com Freire (1989, p. 58), "[...] o ato de estudar, enquanto ato curioso do sujeito diante do mundo é expressão da forma de estar sendo dos seres humanos, como seres sociais, históricos, ser fazedor, transformador, que não apenas sabem, mas sabem que sabem". Desse modo, quando os alunos são o sujeito da própria aprendizagem, "seres fazedores, transformadores", no dizer de Paulo Freire, tomam consciência de que sabem e podem transformar o já feito, construído. Do contrário:

Acomodação ou ajustamento, [...] sintoma de sua desumanização, implica em que, tanto a visão de si mesmo, como a do mundo, não pode absolutizar-se, fazendo-o sentir-se um ser desgarrado e suspenso ou levando-o a julgar o seu mundo algo sobre o que apenas se acha. [...] Daí que a massificação implique no desenraizamento do homem. Na sua "destemporalização". Na sua acomodação. No seu ajustamento. (FREIRE, 1980, p. 41).

Por isso a importância de uma formação, educação que descontrua uma postura de passividade, de acomodação, de ajustamento, de alienação e massificação, para se constituírem seres políticos. O aluno não pode ser tratado como um simples objeto nas mãos do professor, que muitas vezes adota práticas que o leva a essa postura acomodada, desumanizada. É o que Freire chama de "educação bancária", isto é, o educando, ao receber passivamente os conhecimentos, torna-se um depósito do educador. É contra essa educação que ele enuncia a conhecida sentença: "Ensinar não é transferir conhecimentos, mas criar as possibilidades para sua produção ou a sua construção" (FREIRE, 1996, p. 52).

A tarefa do professor é mostrar aos alunos uma pluralidade de discursos. Trabalhar com diferentes contextos, com diferentes possibilidades, partindo da leitura de mundo dos educandos com vistas a conhecer cada vez mais e criticamente a si mesmo e ao mundo, é o que possibilitará uma abordagem que forme sujeitos mais conscientes. Desse modo, sim, o professor pode transformar a sua sala de aula num espaço de descobertas e construção de conhecimentos.

No processo de releitura de si e de suas práticas, os professores põem em jogo as diferentes concepções que têm sobre a aprendizagem, os processos de leitura, a compreensão, as funções dos textos e o universo do discurso. Coloca-se em jogo a 
representação que tem cada docente, não só do desenvolvimento cognitivo e sócio afetivo dos sujeitos a quem vão dirigidos os materiais, mas também dos interesses desses destinatários. Daí decorre a detecção do que é adequado ou inadequado em cada uma das práticas sociais.

Nessa perspectiva de educação, o diálogo deve ocupar papel central, entendido como elemento basilar de qualquer prática social. Para Freire (1996, p. 42), o diálogo:

\begin{abstract}
Consiste no respeito aos educandos, não somente enquanto indivíduos, mas também enquanto expressões de uma prática social. A grande tarefa do sujeito que pensa certo não é transferir, depositar, oferecer, doar ao outro, tomado como paciente de seu pensar a inteligibilidade das coisas, dos fatos, dos conceitos. A tarefa coerente do educador que pensa certo é, exercendo como ser humano a irrecusável prática de inteligir, desafiar o educando com quem se comunica e a quem comunica produzir sua compreensão do que vem sendo comunicado. Não há inteligibilidade que não seja comunicação e intercomunicação e que não se funde na dialogicidade. O pensar certo por isso é dialógico e não polêmico.
\end{abstract}

O diálogo torna-se, portanto, imprescindível em todo contexto, para que possa haver inteligibilidade, construção, crescimento. Dialogar qualifica a capacidade do ser humano de se dirigir ao outro, nas diferenças e nos parâmetros racionais das oposições. Permite também estabelecer uma relação com a lucidez de discernimentos e escolhas. Uma prática importante que não possibilitaria espaço para o ódio, a competição e o aproveitamento negativo de oportunidades para obtenção de ganhos individuais contrários ao bem comum. Com a ausência do diálogo permanente, em todas as esferas das relações humanas, gera-se descompassos, as mazelas das escolhas e exclusões, os absurdos dos procedimentos ilegais, aflorando, consequentemente, a prática das corrupções.

Portanto, a perspectiva freiriana possibilita perceber que à medida que o educador tomar consciência daquilo que deseja com a educação, de sua posição política, articulando conteúdos significativos a uma prática também significativa, se desvinculará da função tradicional de mero transmissor de conteúdos e, consequentemente, da perspectiva do aluno como mero receptor. Um educador deve atuar como mediador, partindo da observação da realidade para, em seguida, propor respostas diante dela, pois, assim, estará contribuindo para a formação de pessoas críticas e participativas na sociedade, caminhando todas em busca da liberdade.

\title{
4 DIÁLOGOS POSSÍVEIS NA EDUCAÇÃO: CORPO, DISCIPLINA E LIBERTAÇÃO
}

Freire (2000, p. 73), em seu livro Pedagogia da indignação, relata episódios sobre o descobrimento da América, mais precisamente sobre os 500 anos da chegada do homem branco a esse continente. Expandindo um pouco os conhecimentos sobre o assunto e tecendo uma análise crítica, o autor mostra que pode-se dizer não ser plausível o uso do termo "descobrimento", mas, mais adequado seria, "conquista" - nada doce e simples - sobre todo um povo que, até hoje, sofre as mazelas desse processo. Não restam dúvidas que foi um marco histórico importante, mas é preciso pôr em relevo as consequências para os povos dominados e a força daqueles que lutaram para que seu povo não fosse dizimado. Esta luta pode ser explicitada como o sonho da liberdade, pois foram seus corpos e almas que lutaram: 
O corpo e a alma da América, o corpo e a alma de seus povos originários, assim como o corpo e a alma dos homens e das mulheres que nasceram no chão americano, filhos e filhas de não importa de que combinações étnicas, o corpo e a alma de mulheres e homens que dizem não à dominação de um Estado sobre o outro, de um sexo sobre o outro, de uma classe social sobre a outra, sabem, o corpo e a alma dos progressistas e das progressistas, o que representou o processo de expansão europeia que trazia em si as limitações que nos eram impostas (FREIRE, 2000, p. 74).

O corpo e a alma, o corpo e as subjetividades que neles habitam. Todos os processos históricos de dominação da humanidade nos mostram a vulnerabilidade que o nosso corpo carrega em se tratando de sermos conquistados docilmente por outrem; em sermos docilizados, disciplinados. De uma forma severa e hostil, o sujeito pode ser aprisionado e escravizado, deixando de perceber a força que tem e os desejos que o move. E isso pode perdurar por longos períodos.

Focando o olhar para além dos relatos de uma "libertação opressora", uma suposta liberdade que diante das ações estabelecidas oprime e escraviza, deixando os seres humanos muitas vezes impossibilitados de viver conforme sua vontade e possibilitando analisar processos de opressão das liberdades mais específicos e sutis, as teorias de Michel Foucault surgem com a perspectiva conhecida como pós-estruturalista, que permitiu a organização de diversos estudos sobre os mais variados setores e campos da vida social e coletiva, ressignificando conceitos.

Foucault tematiza processos que envolvem relações de poder e saber, ressaltando os processos de vigilância e punição predominantes em cada período, e é esse mecanismo de poder que produz tanto o sujeito quanto os objetos de discurso.

O indivíduo é sem dúvida o átomo fictício de uma representação 'ideológica' da sociedade; mas é também uma realidade fabricada por essa tecnologia específica de poder que se chama disciplina [...]. Temos que deixar de descrever sempre os efeitos de poder em termos negativos: ele 'exclui', 'reprime', 'recalca', 'censura', 'abstrai', 'mascara', 'esconde'. Na verdade, o poder produz; ele produz realidade; produz campos de objetos e rituais da verdade. O indivíduo e o conhecimento que dele se pode ter se originam nessa produção (FOUCAULT, 2010b, p. 185).

A partir do momento em que o ser humano está inserido em um convívio social, ele se depara com padrões já estabelecidos, e nem sempre a aceitabilidade por parte do mesmo acontece. Para isso, o controle e a disciplina surgem como forma de mostrar a importância que existe em uma sociedade quando essa prática é executada, pois o oposto (a indisciplina) acaba gerando conflitos entre o coletivo ou até mesmo causando danos pessoais.

Em sua teoria, a escola, enquanto organização social, iguala-se às fábricas, conventos, presídios, hospitais e hospícios no que se refere à natureza da instituição, que se apresenta como elemento fundamental na constituição, formação e definição dos processos de "manipulação" dos sujeitos por outros (FOUCAULT, 2010b).

Mesmo que os objetivos sejam apresentados com diferenças em todas as instituições disciplinares citadas, os atores podem ser vistos como sujeitos em processo de adestramento em todas elas. A escola pode representar uma instituição importante para o ser humano, mas Foucault a explicita como o meio mais eficaz de controle, capaz de exercer seu domínio não somente através do corpo, mas também do olhar, dos movimentos e utilizando da própria consciência. 
A escola, via de regra, demonstra toda uma estrutura organizacional disciplinar que vai desde a disposição das carteiras em fileiras, o cumprimento de horários, grades curriculares, o sequenciamento das atividades, utilização de fardamentos e sirenes e a ordenação da importância/valor do discente por seus resultados e aptidões adquiridas. Ela é operada como instrumento de controle social, utilizando da vigília e punição para manter a ordem e demonstrar a autoridade e respeito à hierarquia.

Um olhar mais apurado ao corpo, citado por várias vezes em parte do trabalho de Foucault, como também por Freire, podemos compreender ser nada mais do que aquilo que foi negado a viver como parte do sujeito, de quem é retirada ou anulada a autonomia à medida que docilizado, disciplinado, impossibilitando, de um ou outro modo, as capacidades de atuar, modificar e transformar de forma consciente o lugar no qual se encontra inserido. É nesse processo de negação do e para o ser que surge uma interdição do corpo para Freire (BRIGHENTE, 2013), como se a atuação natural fosse proibida de se manifestar perante o que lhe é apresentado. Para Freire, nessas condições, o sujeito é visto apenas como objeto, como se lhe fosse negada a capacidade de compreensão da realidade, da sua apreensão e da sua comunicação (FREIRE, 2002; 2005). O ser humano muitas vezes não pode atuar conforme seus instintos, pois existe, em certos meios, uma repressão que o impede de se manifestar, seja de forma verbal ou corporal, causando muitas vezes certa repressão para o ser atuante. A maneira de se expressar de cada sujeito em todo seu conjunto depende, muitas vezes, dos acontecimentos que vivenciou anteriormente na vida, dentro da própria sociedade. Seja no âmbito familiar, na igreja, na comunidade ou até mesmo nas vivências e atuações nas instituições escolares. As repressões, interdições explicitam muito como uma sociedade se apresenta, quais as "regras" sociais, os jogos de verdade. Se uma criança foi reprimida por não executar seus desejos, certamente sofrerá com as consequências que the retornarão no futuro, seja como aluno, filho(a), pai, mãe ou como cidadão atuante na sociedade.

Freire ainda acrescenta que a sociedade brasileira vivenciou a experiência do que ele chamou de "violência da interdição do corpo", dentro de uma realidade social que já surgiu rejeitando o seu próprio corpo (BRIGHENTE, 2013). Mesquida (2008, p. 3318) comenta:

[...] o "outro", na medida em que é negado, deixa de ser, não se realiza como corpo que sente, apreende e se expressa e, por isso mesmo é possuído, coisificado, instrumentalizado, dominado. Esta é a lógica de um sistema que tem a posse como centro e força motriz. A posse de bens materiais, culturais, intelectuais. É precisamente do interior desse sistema que Paulo Freire analisa criticamente a opressão, isto é, a violência contra corpos proibidos de serem, aos quais ele chama de corpos interditados.

Verificando o contexto educacional brasileiro, observamos processos em que homens e mulheres deixam de ser sujeitos de suas histórias, para tornarem-se meros objetos, passando a ter seus corpos interditados e privados de usufruírem seus direitos. São histórias que acompanham os primeiros povos de nossa nação. São negações de valores, acentuadas práticas de preconceitos, discriminações e formas hierárquicas.

Rabinovich (2007, p. 69) destaca que:

O papel do corpo [...] na formação da pessoa humana pressupõe uma educação corporal não domesticadora, que o conceba como um meio de expressar emoções, por isso objetiva desenvolver a criatividade, bem como 
levar as crianças a construir significações a partir de suas vidas. Em suma, trata-se de uma educação cuja metodologia é permeada de características lúdicas, de alegria, de prazer, de fantasia, permitindo que corpo e cognição se desenvolvam de forma articulada.

O corpo - principalmente na infância - é uma ferramenta de suma importância na trajetória da aprendizagem. É através dele que as descobertas vão surgindo e por ele o sujeito infante toma consciência de que ele deve ser explorado na busca de suas respostas, com interações coletivas junto às demais crianças, brincadeiras direcionadas e a questão da afetividade entre elas.

Michel Foucault (2010b), como apontado, coloca a escola, assim como o quartel, a prisão, o manicômio e a fábrica, como instituições disciplinares, que têm objetivo de formar e formatar o sujeito física e mentalmente, moldando-o às normas e valores da sociedade em que está inserido, tornando-o dócil, útil e obediente ao sistema em vigor:

O momento histórico das disciplinas é o momento em que nasce uma arte do corpo humano que visa [...] à formação de uma relação que no mesmo mecanismo o torna mais obediente quanto é mais útil, e inversamente. Formase então uma política das coerções que são um trabalho sobre o corpo, uma manipulação calculada de seus elementos, de seus gestos, de seus comportamentos (FOUCAULT, 2010b, p. 133).

Estas instituições utilizam ferramentas de punição e controle que vão da vigilância até as ações de repreensão e tem como objetivo produzir um tipo específico de sujeito, aquele que será inserido no mercado de trabalho, na vida produtiva. Com Foucault, podemos dizer que, ao contrário do discurso de que a escola é a base para a transformação social e do indivíduo, ela pode servir como centro de manutenção do sistema que impera na sociedade.

No sistema escolar, por vezes, o corpo é encarado como parte distinta da mente e somente a cabeça deve atuar, como se o raciocínio, o pensamento não pudesse se comunicar e não estivesse intrinsecamente relacionado com as demais partes do corpo, ou seja, nessa perspectiva, a mente trabalha e o corpo fica imóvel, favorecendo a docilidade e obediência.

Nesse sentido, Foucault (2007, p. 119) ressalta que:

A disciplina fabrica assim corpos submissos e exercitados, corpos dóceis. A disciplina aumenta as forças do corpo (em termos econômicos de utilidade) e diminui essas mesmas forças (em termos políticos de obediência). Em uma palavra: ela dissocia o poder do corpo; faz dele por um lado uma aptidão, uma capacidade que ela procura aumentar; e inverte por outro lado a energia, a potência que poderia resultar disso, e faz dela uma relação de sujeição estrita. Se a exploração econômica separa a força e o produto do trabalho, digamos que a coerção disciplinar estabelece no corpo o elo coercitivo entre uma dominação acentuada.

Podemos perceber que a disciplina é constituída pelo adestramento dos corpos e, em muitos casos, a escola ensina conteúdos, comportamentos e habilidades através de estratégias que disciplinam os corpos das crianças. Enquanto o aluno for visto no contexto da escola de forma dual (corpo e mente), continuaremos reproduzindo práticas disciplinadoras, deixando de lado a ideia de superação desses padrões estabelecidos.

Foucault (2007, p. 130) aprofunda as discussões trazendo a compreensão 
de controle disciplinar:

[...] não consiste simplesmente em ensinar ou impor uma série de gestos definidos, impõe a melhor relação entre um gesto e a atitude global do corpo, que é sua condição de eficácia e rapidez. No bom emprego do corpo, que permite um bom emprego do tempo, nada deve ficar ocioso e inútil: tudo deve ser chamado a formar o suporte do ato requerido. Um corpo bem disciplinado forma o contexto de realização do mínimo gesto. Uma boa caligrafia, por exemplo, supõe uma ginástica, uma rotina cujo rigoroso código abrange o corpo por inteiro, da ponta do pé á extremidade do indicador.

Muitas vezes as pessoas têm como certo a questão de que uma instituição escolar apenas está presente para repassar conteúdos para os alunos. Há todo um processo de disciplina em jogo, em que, ao se trabalhar a mente, o corpo deve seguir toda uma etapa de aprendizagem, para que "a aprendizagem" seja satisfatória na vida do educando.

Historicamente, o processo de disciplinarização vem sendo alterado no contexto escolar, que parte de processos de punição físicos mais rigorosos e explícitos, passando pelo uso "do exercício, do treinamento silencioso, da correção contínua, por trás das quais uma relação pessoal - no ato da própria punição também - desempenha um papel cada vez maior" (PONGRATZ, 2008, p. 44, grifo do autor) até chegarmos à disciplinarização panóptica, com técnicas novas e mais sutis de controle, a partir da qual o próprio sujeito passa a se autorregular, controlar, disciplinar (PONGRATZ, 2008).

Paulo Freire faz reflexões acerca da educação e defende que essa deveria ter o caráter libertador e não domesticador: "pedagogia que faça da opressão e de suas causas objeto de reflexão dos oprimidos, de que resultará o seu engajamento necessário na luta por sua libertação, em que esta pedagogia se fará e refará" (FREIRE, 2005, p. 34). Ele diz que a libertação do homem oprimido será possível mediante a concepção de educação libertadora que rema contra a dominação.

Para Freire, a educação seria uma práxis capaz de libertar o homem de toda situação de opressão, tornando-o um sujeito crítico e reflexivo através da libertação da sua consciência, capaz de transformar sua realidade e atuar na sociedade de forma efetiva. Propõe, ainda, abandonar a ideia de fazer do homem "vasilhas" e "recipientes" preenchidos com aquilo que julgam ser educação, aquela que defende os interesses do opressor. Em contrapartida, passa a defender a educação por meio da desalienação, da conscientização e da problematização, ou seja, a educação problematizadora alicerçada em questionamentos, diálogo crítico, tomada de consciência da condição existencial do sujeito, que favorece o desenvolvimento do homem como ser transformador e liberto.

Já Pongratz (2008, p. 52) nos provoca a pensar que todo cenário pedagógico está imerso nas contradições sociais da modernidade, as quais "trazem à baila tanto a sujeição quanto a liberdade como contramovimentos determinantes. [...] tornam a práxis pedagógica em uma caminhada sobre a corda bamba - e, ao mesmo tempo, demonstram a impossibilidade de ajustar-se ao status quo social". Partindo dessa perspectiva, podemos nos questionar: Como potencializar o indivíduo, conduzindo-o às suas capacidades máximas? É possível uma educação libertadora, como proposta por Freire, e não disciplinar, como denunciado por Foucault? Qual o limite entre elas? Como repensar a educação a partir dessas provocações? É possível alguma conclusão?

\section{IMPOSSIBILIDADE DE CONCLUIR}

Com base nessas perspectivas teóricas de Foucault e Freire, nas quais este 
artigo se ancora, buscamos refletir teoricamente sobre o papel da educação escolar, buscando compreender se desejamos uma educação disciplinar ou libertadora. Partindo das obras desses autores, é possível notar a importância de as instituições escolares formarem cidadãos críticos, capazes de pensar e refletir suas atitudes, compreendendo suas condições existenciais e o poder que têm de transformar as realidades nas quais estão inseridos.

Podemos indicar a necessidade de pensar uma educação para libertar, não disciplinar. Utópico? Talvez... Mas, de qualquer modo, parece-nos potente apontar a urgência de trabalharmos de modo a compreender cada vez mais os sujeitos e suas necessidades no processo educacional, inquirindo-nos sobre as práticas estabelecidas, as verdades sociais, os conceitos cristalizados, os interesses do mercado e as práticas veladas de opressão.

Os sujeitos que constituem as instituições escolares, nesse sentido, devem estar sempre prontos para proporcionar e impulsionar mudanças, pois isso parece capazes de transformar os sujeitos e a sociedade. A escola deve estar sempre pronta para instigar os sujeitos e fazer despertar, em cada um ali atuando, o que possui de melhor. Como fazer? Seguimos refletindo juntos, o que já é um primeiro movimento! Aqui assumimos a impossibilidade de conclusão e apontamos, ao contrário, a necessidade e desejo de continuidade das problematizações, reflexões e diálogos sobre o tema, caso contrário...

Figura 4 - Ilustração de um sonho da personagem Felipe, referente ao trecho: "[...]havia longas esteiras onde se encontravam crianças, centenas delas, todas diferentes. A esteira entrava num túnel escuro e do outro lado saíam as crianças, todas iguaizinhas, saídas da forma, formadas... E o Corvo Falante cantava: "Formatura. Entram diferentes e saem iguais: profissionais. É assim que um pirralho entra no mercado de trabalho."

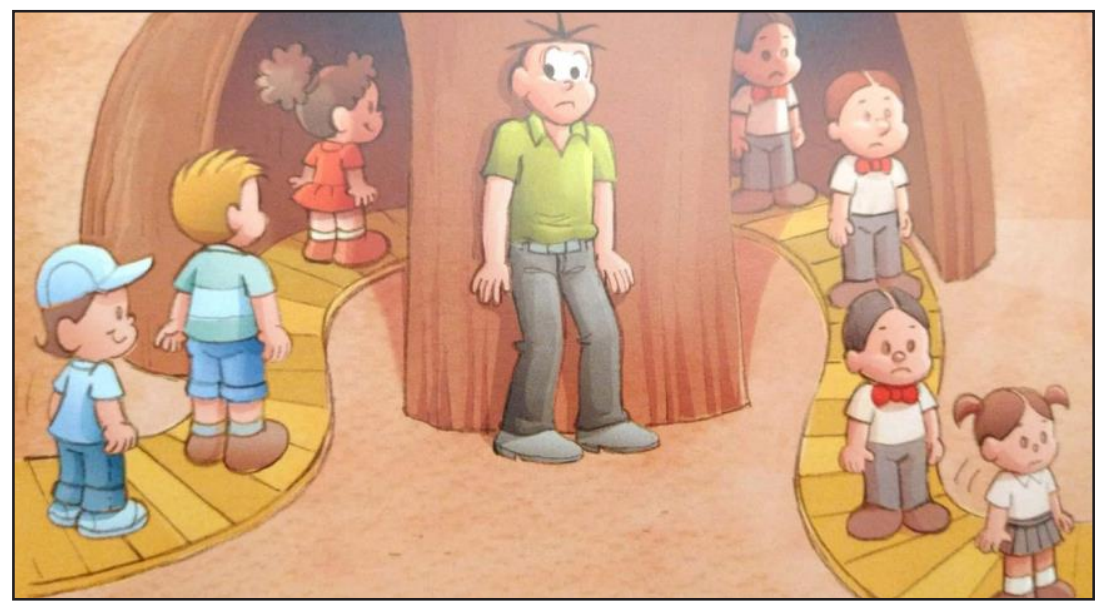

Fonte: Alves (2010, p. 42).

\section{REFERÊNCIAS}

ALVES, R. Pinóquio às avessas: uma estória sobre crianças e escolas para pais e professores. Ilustrações de Maurício de Souza. Campinas, SP: Versus, 2010.

BRIGHENTE, F. Paulo Freire: Corpos Interditados e Negados na Prática Pedagógica. Cadernos de Pesquisa: Pensamento Educacional, v. 8 n. 18, 2013.

FERREIRA, M. M. Salvar corpos, forjar a razão: contributo para uma análise crítica 
da criança e da infância como construção social em Portugal (1880- 1940). Lisboa: Instituto de Inovação Educacional, 2000.

FOUCAULT, M. A História da Sexualidade l: a vontade de saber. Tradução de Maria Thereza da Costa e J. A. Guilhon Albuquerque. Rio de Janeiro: Edições Graal, 1988.

FOUCAULT, M. Microfísica do poder. Rio de Janeiro: Edições Graal, 2010a.

FOUCAULT, M. Vigiar e Punir: nascimento da prisão. Tradução de Raquel Ramalhete. 38. ed. Petrópolis, RJ: Vozes, 2010b.

FREIRE, P. Ação cultural para a liberdade. São Paulo: Paz e Terra, 2002.

FREIRE, P. Educação como prática da Liberdade. Rio de Janeiro: Paz e Terra, 1980

FREIRE, P. Pedagogia do Oprimido. Rio de Janeiro: Paz e Terra, 2005.

FREIRE, P. A importância do ato de ler: em três artigos que se completam. São Paulo: Autores Associados, 1989.

FREIRE, P. Pedagogia da autonomia: saberes necessários à prática educativa. São Paulo: Paz e Terra, 1996.

FREIRE, P. Pedagogia da indignação: cartas pedagógicas e outros escritos. São Paulo: Editora UNESP, 2000.

MESQUIDA, P. Soldados de Cristo, companheiros de índios, educadores de colonos: formação de professores e ação pedagógica dos jesuítas no Brasil, de 1549 a 1759, à luz do Ratio Estudiorum. In: CONGRESSO NACIONAL DE EDUCAÇÃO - EDUCERE, 9., ENCONTRO SUL BRASILEIRO DE PSICOPEDAGOGIA, 3., 2009, Curitiba. Anais... Curitiba: Champagnat, 2009.

PETERS, M. A.; BESLEY, T. (Org.). Por que Foucault? Novas diretrizes para a pesquisa educacional. Porto Alegre: Artmed, 2008.

PONGRATZ, L. A. Liberdade e disciplina: transformações na punição pedagógica. In: PETERS, M. A.; BESLEY, T. (Orgs.). Por que Foucault? Novas diretrizes para a pesquisa educacional. Porto Alegre: Artmed, 2008, p. 40-53. 